\title{
Theoretical Analysis of a Three-Phase Bidirectional Isolated DC-DC Converter Using Phase-Shifted Modulation
}

\author{
Z. Y. Tan ${ }^{1}$, N. M. L. Tan ${ }^{2}$, I. S Hussain ${ }^{3}$ \\ Department of Electrical Power Engineering, Universiti Tenaga Nasional, Malaysia
}

\begin{tabular}{lll}
\hline \hline Article Info & ABSTRACT \\
\cline { 1 - 3 } Article history: & $\begin{array}{l}\text { A three-phase bidirectional isolated dc-de converter consists of two six-pulse } \\
\text { two-level active converters that enable bidirectional power flow by } \\
\text { introducing a lag phase-shift angle of one converter with respect to the other } \\
\text { Received Nov 26, 2017 } \\
\text { Revised Jan 3, 2018 } \\
\text { Accepted Jan 18, 2018 }\end{array} \quad \begin{array}{l}\text { converter. This paper explains the operating modes of a three-phase } \\
\text { bidirectional isolated dc-dc converter in detail, taking into account the } \\
\text { transfer of energy between the dc voltage sources and high-frequency ac } \\
\text { inductances in the three-phase bidirectional isolated dc-dc converter. The } \\
\text { power flow of the dc-dc converter is also examined based on the operating } \\
\text { modes }\end{array}$ \\
\hline Phase-shifted modulation &
\end{tabular}

Copyright $\odot 2018$ Institute of Advanced Engineering and Science. All rights reserved.

Corresponding Author:

Z. Y. Tan,

Department of Electrical Power Engineering,

Universiti Tenaga Nasional, Malaysia

Email: zhongyiht@gmail.com

\section{INTRODUCTION}

DC-DC converters are classified into single- or three-phase circuit configurations. From singlephase configurations, these converters are classified into full- or half-bridge. Half-bridge circuits need only half the number of power electronic switches required in full-bridge. Authors of [1] carried out simulation on this topology and discovered that it has major advantages such as reduced switching losses and low electromagnetic interference. The three-phase $\mathrm{dc}-\mathrm{dc}$ converter typically consist of six-pulse two-level or neutral-point-clamp converters. The converters are also differentiated by the direction of power flow unidirectional and bidirectional. Unidirectional converters only allow single direction of power flow, whereas bidirectional converters enable energy to transfer between its input and output. Bidirectional converters are assorted into isolated and non-isolated topology. The isolated type converters provide a galvanic isolation and voltage matching at the $\mathrm{DAB}$ [2] and [3]. In the isolated bidirectional converter, both sides of the converter employ active bridges to form a dual active bridge (DAB). These DC-DC converters are being widely used in many areas such as in solid-state transformers for the distribution systems, renewable energy systems, battery energy storage systems for grid and electric vehicle [4]-[12]. Non-isolated topologies have aso been considered for grid-interconnection of dc distribution systems [13]-[15].

The single-phase dual active bridge (SPDAB) has gained popularity due to the improvements in $5^{\text {th }}$ generation trench-gate Insulated Gate Bipolar Transistors (IGBTs) technology that results in a high converter efficiency of up to $97 \%$ [2]. Its power flow is controlled by applying various types of modulation techniques. The common techniques include the phase-shift, triangular and trapezoidal modulation techniques. The efficiency of a converter at different power transfer range depend on switching techniques at the power 


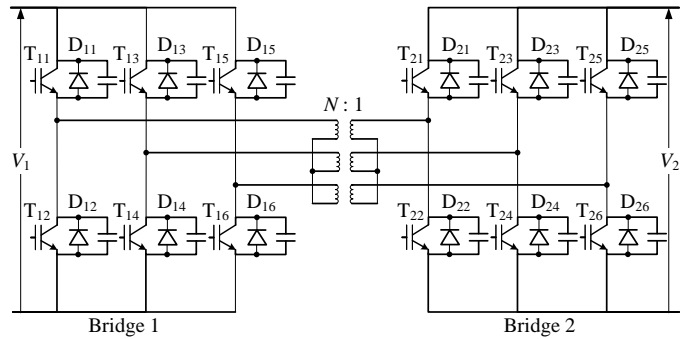

(a)

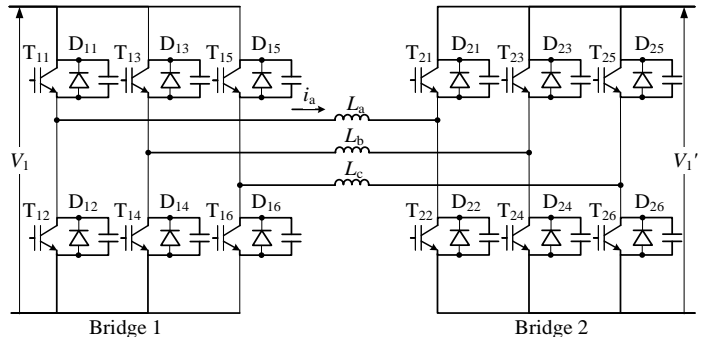

(b)

Figure 1. A three-phase dual active bridge.

electronic switches. The phase-shifted modulation has an advantage such that zero-voltage switching (ZVS). However, there is a limitation, whereby this technique produces high circulating current when operate far from the dc-dc converter's nominal operating point [10]. Triangular modulation is being applied on a SPDAB to ensure ZVS at all switches. It is also suitable for the use in applications that has high voltage differences between the input and output of the converters. Trapezoidal modulation is best being used in applications which has low voltage differences between input and the output [10], [11], and [16]. It has more frequent hard-switching turn-off processes as compared to triangular modulation. Another method is to combine all three techniques mentioned above, also known as optimal modulation scheme. This scheme is being used for the yield of higher efficiency on the SPDAB. This hyrbrid modulation strategy could also be applied on a three-phase bidirectional isolated dc-dc converter (TPDAB) [17].

The TPDAB is more suitable for a high-power density application, as it has several advantages including the ability of operation at wide range of voltage and power, low turn-off peak currents in the power switches, higher efficiency, and reduced filter volume and costs [9]. They are employed for high-power applications energy storage systems that are grid connected or employed in electric vehicles [17] and [18]. Eventhough the hybrid modulation strategy can improve the efficiency of the TPDAB over a wide range of voltage level and power transfer, the mouldation strategy need high computation power. In addition, the challenge of the converter is in the implementation of a three-phase high-frequency transformer. Nevertheless, the converter is gaining interest for application that requires high-power density.

This paper presents the operation modes of the TPDAB based on phase-shift modulation. Although the authors in [9] presented the topology and discussed the power transfer modes of the TPDAB, this paper presents the mode-by-mode analysis for the first half of the TPDAB operations by considering the energy transfer between the dc voltage sources and the high-frequency ac inductances. This analysis is intended to be an initial reference and to aid students and researchers to understand the operating principles of the TPDAB. Finally, this paper also discusses the power flow analysis of the TPDAB.

\section{CIRCUIT CONFIGURATION OF A TPDAB}

Figure 1a shows the circuit configuration of a TPDAB. It consists of bridge 1 and bridge 2 . Each of the bridges are connected to a dc voltage source, where $V_{1}$ represents the voltage source at bridge 1 , and $V_{2}$ is the voltage source at bridge 2 . At each of the bridges, there are six IGBTs as the power semiconductor switches, with a freewheeling diode and a snubber capacitor connected in parallel to each switch. The freewheeling diodes are being used in the implementation of a TPDAB so that it could provide a path to transfer the current when IGBTs are gated to turn off, and the snubber capacitors are connected to achieve ZVS operation. A three-phase transformer with high-frequency operation is employed to provide galvanic isolation while increasing the power density. The transformer turn ratio, $d$ is $N_{1}: N_{2}$, where $N_{1}$ is the number of turns on bridge 1 side and $N_{2}$ is the number of turns on bridge 2 side. The high frequency applied to this transformer is usually above $20 \mathrm{kHz}$. It is designed to prevent audible noises, and to reduce the magnetic component size of the converter. At bridge $1, S_{11}$ to $S_{16}$ are IGBTs, and $D_{11}$ to $D_{16}$ are freewheeling diodes. Since the circuit is symmetrical, bridge 2 has similar components and topology, where, $S_{21}$ to $S_{26}$ are IGBTs, and $D_{21}$ to $D_{26}$ are freewheeling diodes. The first subscript number represents the bridge number, either 1 or 2 , whereas the second subscript number represents the switch number, from 1 to 6 . 
Table 1. Operating Components For Six Modes

\begin{tabular}{lcccccc}
\hline Mode No. & $\mathbf{1}$ & $\mathbf{2}$ & $\mathbf{3}$ & $\mathbf{4}$ & $\mathbf{5}$ & $\mathbf{6}$ \\
\hline Bridge 1 & $\mathrm{D}_{11}, \mathrm{~T}_{11}$ & $\mathrm{~T}_{11}$ & $\mathrm{~T}_{11}$ & $\mathrm{~T}_{11}$ & $\mathrm{~T}_{11}$ & $\mathrm{~T}_{11}$ \\
& $\mathrm{~T}_{14}$ & $\mathrm{~T}_{14}$ & $\mathrm{~T}_{14}$ & $\mathrm{~T}_{14}$ & $\mathrm{D}_{13}, \mathrm{~T}_{13}$ & $\mathrm{~T}_{13}$ \\
& $\mathrm{~T}_{15}$ & $\mathrm{~T}_{15}$ & $\mathrm{D}_{16}, \mathrm{~T}_{16}$ & $\mathrm{~T}_{16}$ & $\mathrm{~T}_{16}$ & $\mathrm{~T}_{16}$ \\
Bridge 2 & $\mathrm{D}_{22}, \mathrm{~T}_{22}$ & $\mathrm{D}_{21}$ & $\mathrm{D}_{21}$ & $\mathrm{D}_{21}$ & $\mathrm{D}_{21}$ & $\mathrm{D}_{21}$ \\
& $\mathrm{D}_{24}$ & $\mathrm{D}_{24}$ & $\mathrm{D}_{24}$ & $\mathrm{D}_{24}$ & $\mathrm{D}_{24}, \mathrm{~T}_{24}$ & $\mathrm{D}_{23}$ \\
& $\mathrm{D}_{25}$ & $\mathrm{D}_{25}$ & $\mathrm{D}_{25}, \mathrm{~T}_{25}$ & $\mathrm{D}_{26}$ & $\mathrm{D}_{26}$ & $\mathrm{D}_{26}$ \\
\hline
\end{tabular}

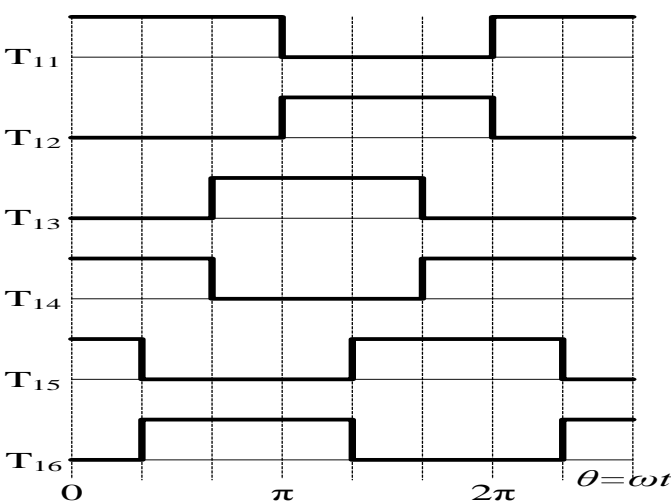

(a)

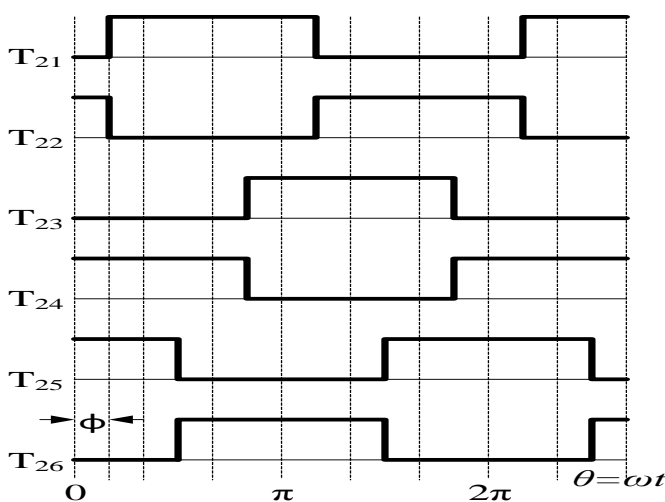

(b)

Figure 2. Gating signal control of a TPDAB based on phase-shift modulation. (a) Bridge 1. (b) Bridge 2.

Figure $1 \mathrm{~b}$ shows the circuit configuration of the TPDAB referred to the bridge-1-side. All components remained the same as in Figure 1a. However, the dc voltage source at bridge 2 is now referred to bridge-1-side and it is denoted as $V_{1}{ }^{\prime}\left(=d V_{1}\right)$. The three-phase transformer is now represented as three individual transformer leakage reactance at each of the phases. The three-phase transformer reactances can be represented as leakage inductors as derived in [3] and [9]. It is seen that through transformation of the simplified single equivalent circuit, the transformer reactance, $L$ can be reduced to $L_{\sigma}=d^{2} L_{\mathrm{sl}}+L_{\mathrm{pl}}$, where $L_{\mathrm{sl}}$ and $L_{\mathrm{pl}}$ are the primary and secondary leakage inductances, with the assumptions of $i_{\mathrm{as}}=i_{\mathrm{ap}}=i(\phi)$ for phase A. The per phase leakage inductance of the transformer is used as the power transfer element as described in Section 4.

\section{ANALYSIS OF THE TPDAB OPERATING MODES}

Table 1 presents the switching modes for the TPDAB based on phase-shift modulation [9]. Typically, there are twelve modes of operation. However, due to the symmetry of the waveform, the analysis is carried out for the first six of the operating modes ( 0 to $\pi$ ). In the analysis, power is assumed to flow from bridge 1 to bridge 2 , with the phase-shift angle $\phi$ being positive.

Figure 2 shows the gating signal control of the IGBTs on both bridge 1 and bridge 2 deduced from Table 1. Each of the switches conduct for $180^{\circ}$ per cycle. When the power flow is zero, $\mathrm{T}_{11}$ is turned on at the same time as $\mathrm{T}_{21} . \mathrm{T}_{12}$ and $\mathrm{T}_{22}$ remains off. To ensure power to flow from bridge 1 to bridge 2 , a lag phaseshift angle, $\phi$ is introduced in bridge 2 . The relationship of average power transfer with the phase-shift angle is explained in Section 4.

Referring to Figure 1, the difference between the voltages in bridge 1 and bridge 2 determines the rate of change of three-phase transformer currents, $i_{a}, i_{b}, i_{c}$, through leakage inductors, $L_{\mathrm{a}}, L_{\mathrm{b}}$, and $L_{\mathrm{c}}$. A balanced TPDAB circuit is assumed, where $i_{a}+i_{b}+i_{c}=0$. Figure 4 shows the idealized operating waveforms of the TPDAB on phase A. These waveforms show the ac voltage waveform for bridge 1 and bridge 2 , and the ac current of bridge 1 . It is important to take note that there is a $120^{\circ}$ phase-shift between phases $\mathrm{A}, \mathrm{B}$, and $\mathrm{C}$. The phase current $i_{\mathrm{a}}$ in Figure 4 demonstrates the charging and discharging mode of inductors $L_{\mathrm{a}}, L_{\mathrm{b}}$ and $L_{\mathrm{c}}$. The change in voltage across an inductor is proportional to the rate of change of current in the inductor. The inductor stores and supplies energy when the product of the change in voltage and current flow in it is positive and negative, respectively. The operating mode analysis in this paper assumes the commutations of current in the snubber capacitors are instantaneous. 


\subsection{Mode $1(0<\theta \leq \phi)$}

Figure 3a presents mode 1 operation of the TPDAB. In this mode, transistors $\mathrm{T}_{11}, \mathrm{~T}_{14}, \mathrm{~T}_{15}$, and $\mathrm{T}_{22}$ are turned on. Energy from source $V_{1}$ and $L_{\mathrm{c}}$ is transferred to source $V_{1}$ ' and inductor $L_{\mathrm{b}}$ when the current flows through the route of $\mathrm{T}_{15}-\mathrm{D}_{25}-\mathrm{D}_{24}-\mathrm{T}_{14}$. Initially, inductor $L_{\mathrm{a}}$ also supplies energy to $V_{1}$ ' via the current

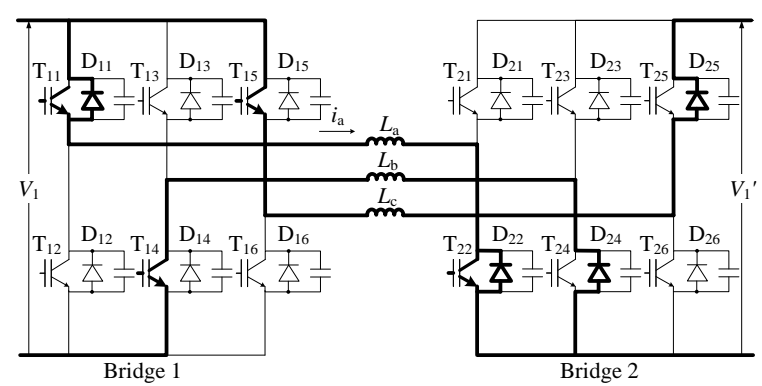

(a)

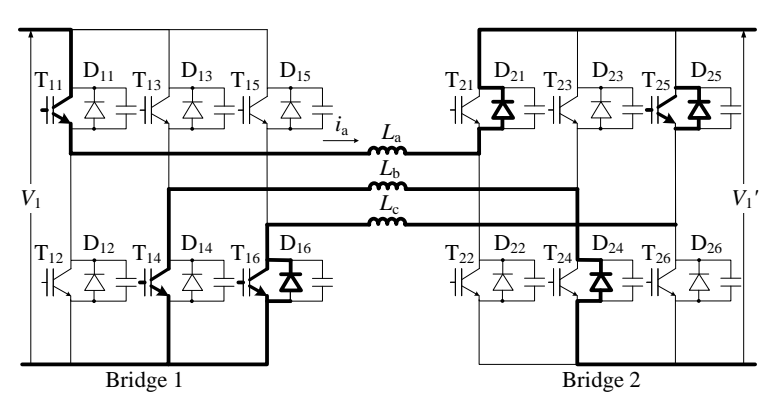

(c)

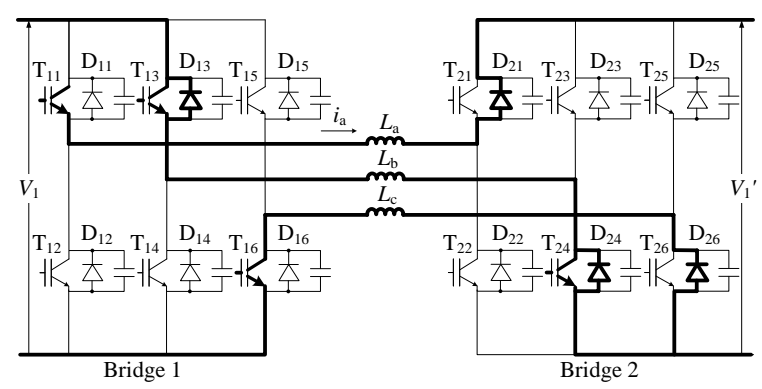

(e)

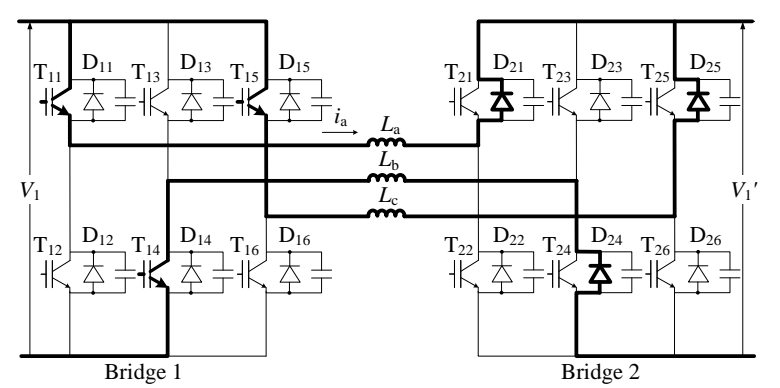

(b)

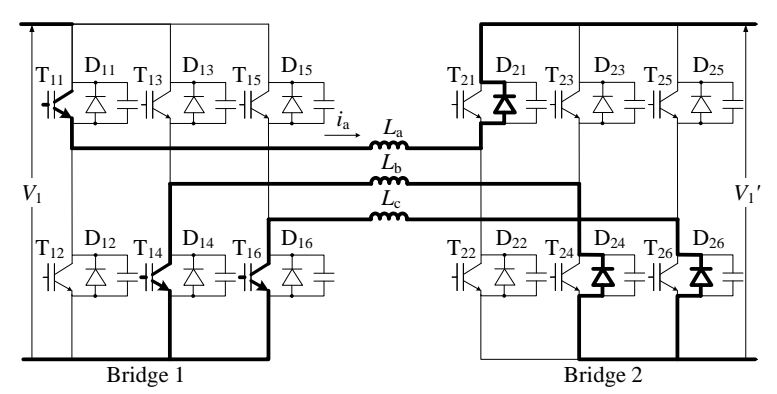

(d)

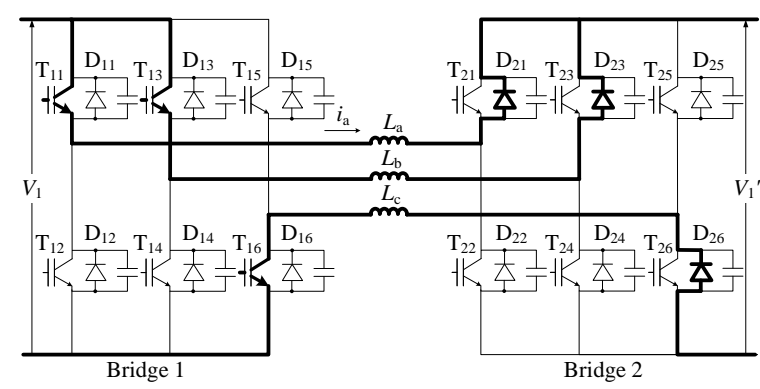

(f)

Figure 3. The main operating modes of the TPDAB. (a) Mode 1. (b) Mode 2. (c) Mode 3. (d) Mode 4. (e) Mode 5. (f) Mode 6.

flow route of $\mathrm{D}_{25}-\mathrm{D}_{22}-\mathrm{D}_{11}-\mathrm{T}_{15}$. Once the current in $L_{\mathrm{a}}$ reduces to zero, $\mathrm{T}_{11}$ will start to conduct current and $L_{\mathrm{a}}$ is charged from source $V_{1}$ through the current route of $\mathrm{T}_{11}-\mathrm{T}_{22}-\mathrm{D}_{24}-\mathrm{T}_{14}$.

\subsection{Mode $2(\phi<\theta \leq \pi / 3)$}

Figure $3 \mathrm{~b}$ shows mode 2 operation of the TPDAB. During the mode, transistors, $\mathrm{T}_{11}, \mathrm{~T}_{14}$, and $\mathrm{T}_{15}$ are turned on. Energy is transferred from Source $V_{1}$ to $V_{1}$ ' via the route of $\mathrm{T}_{11}-\mathrm{D}_{21}-\mathrm{D}_{24}-\mathrm{T}_{14}$ and $\mathrm{T}_{15}-\mathrm{D}_{25}-\mathrm{D}_{24}-\mathrm{T}_{14}$. The rate of change of current in the inductors are constant. Ideally, no energy is stored in or supplied by the inductors.

\subsection{Mode $3(\pi / 3<\theta \leq \phi+\pi / 3)$}

Figure $3 \mathrm{c}$ presents mode 3 operation of the TPDAB. In this mode, transistors $\mathrm{T}_{11}, \mathrm{~T}_{14}, \mathrm{~T}_{16}$, and $\mathrm{T}_{25}$ are turned on. Energy from source $V_{1}$ and $L_{\mathrm{b}}$, are transferred to source $V_{1}$ ' and inductor $L_{\mathrm{a}}$ when the 
current flows through the route of $\mathrm{T}_{11}-\mathrm{D}_{21}-\mathrm{D}_{24}-\mathrm{T}_{14}$. Initially, inductor $L_{\mathrm{c}}$ supplies energy to $V_{1}$ ' via the current flow route of $\mathrm{T}_{11}-\mathrm{D}_{21}-\mathrm{D}_{24}-\mathrm{T}_{14}$. Once the current in $L_{\mathrm{c}}$ reduces to zero, the direction of current in phase $\mathrm{C}$ changes from positive to negative. Inductor $L_{\mathrm{c}}$ is charged from source $V_{1}$ through the current route of $\mathrm{T}_{11^{-}}-\mathrm{D}_{21^{-}}$ $\mathrm{T}_{25}-\mathrm{T}_{16}$

\subsection{Mode $4(\phi+\pi / 3<\theta \leq 2 \pi / 3)$}

Figure $3 \mathrm{~d}$ shows mode 4 operation of the TPDAB. During the mode, transistors, $\mathrm{T}_{11}, \mathrm{~T}_{14}$, and $\mathrm{T}_{16}$ are turned on. Energy is transferred from Source $V_{1}$ to $V_{1}$ ' via the route of $\mathrm{T}_{11}-\mathrm{D}_{21}-\mathrm{D}_{24}-\mathrm{T}_{14}$ and $\mathrm{T}_{11}-\mathrm{D}_{21}-\mathrm{D}_{26}-\mathrm{T}_{16}$. The rate of change of current in the inductors are constant. Ideally, no energy is stored in or supplied by the inductors.

\subsection{Mode $5(2 \pi / 3<\theta \leq \phi+2 \pi / 3)$}

Figure $3 \mathrm{e}$ illustrates mode 5 operation of the TPDAB. In this mode, transistors $\mathrm{T}_{11}, \mathrm{~T}_{13}, \mathrm{~T}_{16}$, and $\mathrm{T}_{24}$ are turned on. Energy from source $V_{1}$ and $L_{\mathrm{a}}$ is transferred to source $V_{1}$ ' and inductor $L_{\mathrm{c}}$ when the current flows through the route of $\mathrm{T}_{11}-\mathrm{D}_{21}-\mathrm{D}_{26}-\mathrm{T}_{16}$. Initially, inductor $L_{\mathrm{b}}$ also supplies energy to $V_{1}$ ' via the current flow route of $\mathrm{D}_{21}-\mathrm{D}_{24}-\mathrm{D}_{13}-\mathrm{T}_{11}$. Once the current in $L_{\mathrm{b}}$ reduces to zero, $\mathrm{T}_{13}$ will start to conduct current and $L_{\mathrm{b}}$ is charged from source $V_{1}$ through the current route of $\mathrm{T}_{13}-\mathrm{T}_{24}-\mathrm{D}_{26}-\mathrm{T}_{16}$.

\subsection{Mode $6(\phi+2 \pi / 3<\theta \leq \pi)$}

Figure $3 \mathrm{f}$ shows mode 6 operation of the TPDAB. During the mode, transistors, $\mathrm{T}_{11}, \mathrm{~T}_{13}$, and $\mathrm{T}_{16}$ are turned on. Energy is transferred from Source $V_{1}$ to $V_{1}$ ' via the route of $\mathrm{T}_{11}-\mathrm{D}_{21}-\mathrm{D}_{26}-\mathrm{T}_{16}$ and $\mathrm{T}_{13}-\mathrm{D}_{23}-\mathrm{D}_{26}-\mathrm{T}_{16}$. The rate of change of current in the inductors are constant. Ideally, no energy is stored in or supplied by the inductors.

\section{POWER FLOW ANALYSIS}

Equation (1) shows the equivalent leakage inductance of the TPDAB, where $X_{L, e q}$ is the overall leakage reactance at the ac side of bridge 1 . Whereas, individual leakage reactance for phases $\mathrm{A}, \mathrm{B}$, and $\mathrm{C}$ are represented by $X_{L}$. For every operating mode, since current in two out of three phase legs flow in the same direction, thus the reactances are parallel to each other, yielding the formula $X_{L} / 2$.

$X_{L, e q}=X_{L}+\frac{X_{L}}{2}=\frac{3 X_{L}}{2}$

By applying voltage divider rule, the voltages across all three phases during mode 1 operation $(0<\theta \leq \phi)$ are obtained as shown in Equation (2) and (3):

$$
\begin{aligned}
& v_{a p}=v_{c p}=\frac{X_{L}}{2} / \frac{3 X_{L}}{2} \times V_{1}=\frac{X_{L}}{2} \times \frac{2 V_{1}}{3 X_{L}}=\frac{V_{1}}{3} \\
& v_{b p}=X_{L} / \frac{3 X_{L}}{2} \times-V_{1}=X_{L} \times-\frac{2 V_{1}}{3 X_{L}}=-\frac{2}{3} V_{1}
\end{aligned}
$$

The current flowing through the inductor at phase A in mode 1 operation can be defined using piecewiselinear equations:

$i_{a p}=i_{a s}=i(\theta)$

$i(\theta)=i(0)+\frac{V_{1}+d V_{2}}{3 \omega L_{a}}(\theta)$

where $V_{1}$ is the bridge $1 \mathrm{dc}$ voltage, $\omega$ is the angular frequency, $L_{\mathrm{a}}$ is the transformer leakage inductance of phase $\mathrm{A}, d$ is the transformer turns ratio, and $\phi$ is the phase-shift angle. 
By applying voltage divider rule, the voltages across all three phases during mode 2 operation $(\phi<\theta \leq \pi / 3)$ are:

$v_{a p}=v_{c p}=\frac{X_{L}}{2} / \frac{3 X_{L}}{2} \times V_{1}=\frac{X_{L}}{2} \times \frac{2 V_{1}}{3 X_{L}}=\frac{V_{1}}{3}$

$v_{b p}=\frac{X_{L}}{\frac{3 X_{L}}{2}} \times-V_{1}=X_{L} \times-\frac{2 V_{1}}{3 X_{L}}=-\frac{2}{3} V_{1}$

The current flowing through the inductor at phase A in mode 2 operation can be defined using piecewiselinear equations, also by referring to Equation (4), the equation is:

$i(\theta)=i(\phi)+\frac{V_{1}-d V_{2}}{3 \omega L_{a}}(\theta-\phi)$

By applying voltage divider rule, the voltages across all three phases during mode 3 operation $(\pi / 3<\theta \leq \phi+$ $\pi / 3)$ are:

$v_{b p}=v_{c p}=\frac{X_{L}}{2} / \frac{3 X_{L}}{2} \times-V_{1}=\frac{X_{L}}{2} \times-\frac{2 V_{1}}{3 X_{L}}=-\frac{V_{1}}{3}$

$v_{a p}=\frac{X_{L}}{\frac{3 X_{L}}{2}} \times V_{1}=X_{L} \times \frac{2 V_{1}}{3 X_{L}}=\frac{2}{3} V_{1}$

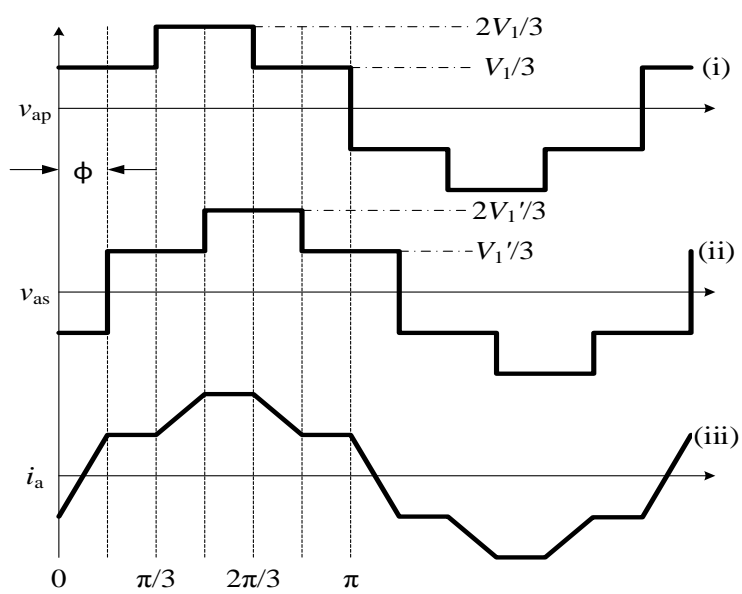

Figure 4: Idealized operating waveforms of TPDAB on phase A.

(a) Bridge 1 ac voltage; (b) Bridge 2 ac voltage; (c) Bridge 1 ac current.

The current flowing through the inductor at phase $\mathrm{A}$ in mode 3 operation can be defined using piecewiselinear equations, also by referring to Equation (4), the equation is:

$i(\theta)=i\left(\frac{\pi}{3}\right)+\frac{2 V_{1}-d V_{2}}{3 \omega L_{a}}\left(\theta-\frac{\pi}{3}\right)$ 
By applying voltage divider rule, the voltages across all three phases during mode 4 operation $(\phi+\pi / 3<\theta \leq$ $2 \pi / 3$ ) are:

$$
\begin{aligned}
& v_{b p}=v_{c p}=\frac{X_{L}}{2} / \frac{3 X_{L}}{2} \times-V_{1}=\frac{X_{L}}{2} \times-\frac{2 V_{1}}{3 X_{L}}=-\frac{V_{1}}{3} \\
& v_{a p}=X_{L} / \frac{3 X_{L}}{2} \times V_{1}=X_{L} \times \frac{2 V_{1}}{3 X_{L}}=\frac{2}{3} V_{1}
\end{aligned}
$$

The current flowing through the inductor at phase A in mode 4 operation can be defined using piecewiselinear equations, also by referring to Equation (4), the equation is:

$i(\theta)=i\left(\phi+\frac{\pi}{3}\right)+\frac{2 V_{1}-2 d V_{2}}{3 \omega L_{a}}\left(\theta-\phi-\frac{\pi}{3}\right)$

By applying voltage divider rule, the voltages across all three phases during mode 5 operation $(2 \pi / 3<\theta \leq \phi+$ $2 \pi / 3$ ) are:

$$
\begin{aligned}
& v_{a p}=v_{b p}=\frac{X_{L}}{2} / \frac{3 X_{L}}{2} \times V_{1}=\frac{X_{L}}{2} \times \frac{2 V_{1}}{3 X_{L}}=\frac{V_{1}}{3} \\
& v_{c p}=X_{L} / \frac{3 X_{L}}{2} \times-V_{1}=X_{L} \times-\frac{2 V_{1}}{3 X_{L}}=-\frac{2}{3} V_{1}
\end{aligned}
$$

The current flowing through the inductor at phase A in mode 5 operation can be defined using piecewiselinear equations, also by referring to Equation (4), the equation is:

$i(\theta)=i\left(\frac{2 \pi}{3}\right)+\frac{V_{1}-2 d V_{2}}{3 \omega L_{a}}\left(\theta-\frac{2 \pi}{3}\right)$

By applying voltage divider rule, the voltages across all three phases during mode 6 operation $(\phi+2 \pi / 3<\theta \leq$ $\pi)$ are:

$$
\begin{aligned}
& v_{a p}=v_{b p}=\frac{X_{L}}{2} / \frac{3 X_{L}}{2} \times V_{1}=\frac{X_{L}}{2} \times \frac{2 V_{1}}{3 X_{L}}=\frac{V_{1}}{3} \\
& v_{c p}=X_{L} / \frac{3 X_{L}}{2} \times-V_{1}=X_{L} \times-\frac{2 V_{1}}{3 X_{L}}=-\frac{2}{3} V_{1}
\end{aligned}
$$

The current flowing through the inductor at phase A in mode 6 operation can be defined using piecewiselinear equations, also by referring to Equation (4), the equation is:

$$
i(\theta)=i\left(\phi+\frac{2 \pi}{3}\right)+\frac{V_{1}-d V_{2}}{3 \omega L_{a}}\left(\theta-\frac{2 \pi}{3}-\phi\right)
$$

Thus, by equating Equation (5) and (20), whereby $i(0)=-i(\pi)$, and solving it, Equation (21) is obtained as shown below [9]:

$$
i(0)=\frac{V_{1}}{2 \omega L_{a}}\left(\frac{2 \phi}{3}-\frac{5 \pi}{9}\right)+\frac{d V_{2}}{2 \omega L_{a}}\left(\frac{4 \pi}{9}-\frac{\phi}{3}\right)
$$


The dc-source current is being reconstructed by the input bridge switching function using $i(\theta)$. Thus, the average output power when $0 \leq \phi \leq \pi / 3$ is [9]:

$P_{o}=\frac{V_{1}^{2}}{\omega L} d \phi\left(\frac{2}{3}-\frac{\phi}{2 \pi}\right)$

For the duration of $\pi / 3 \leq \phi \leq 2 \pi / 3$, the average output power is [9]:

$P_{o}=\frac{V_{1}^{2}}{\omega L} d\left(\phi-\frac{\phi^{2}}{\pi}-\frac{\pi}{18}\right)$

\section{CONCLUSION}

This paper has discussed the operation modes of the three-phase dual-active bridge (TPDAB) based on phase-shift modulation. It considers the transfer of energy between the dc voltage sources and highfrequency ac inductances in the three-phase bidirectional isolated dc-dc converter. Finally, the mathematical modesl of the transformer voltage and current are analysed, leading to the model of the average power flow in the TPDAB, that is based on first principles.

\section{ACKNOWLEDGEMENTS}

The authors would like to thank the Ministry of Higher Education and Universiti Tenaga Nasional for providing financial supports through FRGS Project No. FRGS/1/2017/TK04/UNITEN/02/4 and BOLD Grant Project No. 10289176/B/9/2017/48, respectively.

\section{REFERENCES}

[1] V. V. S. K. Bhajana, "Simulation Based Performance analysis of Active Clamp DHB ZVZCS Bidirectional DC-DC converter for Low Power Applications", International Journal of Power Electronics and Drive System (IJPEDS), vol. 2, no. 3, pp. 345-352, Sep. 2012.

[2] N. M. L. Tan, T. Abe, H. Akagi, "Topology and Application of Bidirectional Isolated DC-DC Converters", 8th International Conference on Power Electronics - ECCE Asia, WeF2-5, pp. 1039-1046, 2011.

[3] M. H. Kheraluwala, R. W. Gascoigne, D. M. Divan, and E. D. Baumann, "Performance characterization of a highpower dual active bridge dc-to-dc converter," IEEE Trans. Ind. Appl., vol. 28, no. 6, pp. 1294-1301, Nov./Dec. 1992.

[4] S. B. Kjaer, J. K. Pedersen, and F. Blaabjerg, "A review of a single-phase grid-connected inverters for photovoltaic modules," IEEE Trans. Ind. Appl., vol. 41, no. 5, pp. 1292-1306, Sept./Oct. 2005.

[5] F. Blaabjerg, Z. Chen, and S. Baekhoej, "Power electronics as efficient interface in dispersed power generation system," IEEE Trans. Power Electron., vol. 19, no. 5, pp. 1184-1194, Sept. 2004.

[6] G. J. Torvetjonn, T. M. Undeland, O. R. Schmidt, and J. H. Bryde, "A dc-dc converter topology with phase shift control and lossless snubbers for use in a 200 A battery charger working on $400 \mathrm{~V}$ mains," in Proc. 17th. Int. Telecommun. Energy Conf. (INTELEC), Nov. 1995, pp. 489-495.

[7] N. M. L. Tan, S. Inoue, A. Kobayashi, and H. Akagi, "Voltage balancing of a 320-V, 12-F electric double-layer capacitor bank combined with a 10-kW bidirectional isolated dc-dc converter," IEEE Trans. Power Electron., vol. 23 , no. 6, pp. 2755-2765, Nov. 2008

[8] N. M. L. Tan, T. Abe, and H. Akagi, "Design and performance of a bidirectional isolated dc-dc converter for a battery energy storage system," to be published in IEEE Trans. Power Electron., 2011.

[9] R. W. De Doncker, D. M. Divan, and M. H. Kheraluwala, "A three-phase soft-switched high-power-density dc/dc converter for high power applications," IEEE Trans. Ind. Appl., vol. 27, no. 1, pp. 63-73, Feb. 1991.

[10] F. Krismer, "Modeling and optimization of bidirectional dual active bridge dc-dc converter topologies," Ph.D. dissertation, Power Electron. Syst. Lab. (PES), ETH Zurich, Zurich, Switzerland, 2010.

[11] N. Schibli, "Symmetrical multilevel converters with two quadrant DC-DC feeding," Ph.D. dissertation, Ecole Polytechnique Federale de Lausanne, Ind. Electron. Lab., Lausanne, Switzerland, 2000.

[12] S. Inoue and H. Akagi, "A bidirectional isolated dc-dc converter as a core circuit of the next-generation mediumvoltage power conversion system," IEEE Trans. Power Electron., vol. 22, no.2, pp. 535-542, Mar. 2007.

[13] D. Dong, I. Cvetkovic, D. Boroyevich, W. Zhang, R. Wang, and P. Mattavelli, "Grid-interface bidirectional converter for residential DC distribution systems-Part 1: High-density two-stage topology," IEEE Trans. Power Electron., vol. 28, no. 4, pp. 1655-1666, Apr. 2013.

[14] D. Dong, I. Cvetkovic, D. Boroyevich, W. Zhang, R. Wang, and P. Mattavelli, "Grid-interface bidirectional converter for residential DC distribution systems-Part 2: AC and DC interface design with passive components minimization," IEEE Trans. Power Electron., vol. 28, no. 4, pp. 1667-1679, Apr. 2013. 
[15] S. Jaisudha, S. Srinivasan, G. Kanimozhi, "Bidirectional Resonant DC-DC Converter for Micorgrid Application", International Journal of Power Elctronics and Drive System (IJPEDS), vol. 8, no. 4, pp. 1548-1561, Dec. 2017.

[16] H. Zhou and A. M. Khambadkone, "Hybrid modulation for dual-active-bridge bidirectional converter with extended power range for ultracapacitor application,” IEEE Trans. Ind. Appl., vol. 45, no. 4, pp. 1434-1442, July/Aug. 2009.

[17] H. V. Hoek, M. Neubert, and R. W. De Doncker, "Enhanced Modulation Strategy for a Three-Phase Dual Active Bridge-Boosting Efficiency of an Electric Vehicle Converter, "IEEE Trans. Power Electron., vol. 28, no. 12, pp. 5499-5507, Dec. 2013.

[18] S. T. P. Engel, N. Soltau, H. Stagge, and R. W. De Doncker, "Dynamic and Balanced Control of Three-Phase HighPower Dual-Active Bridge DC-DC Converters in DC-Grid Applications," IEEE Trans. Power Electron., vol. 28, no. 4, pp. 1880-1889, Apr. 2013.

\section{BIOGRAPHIES OF AUTHORS}
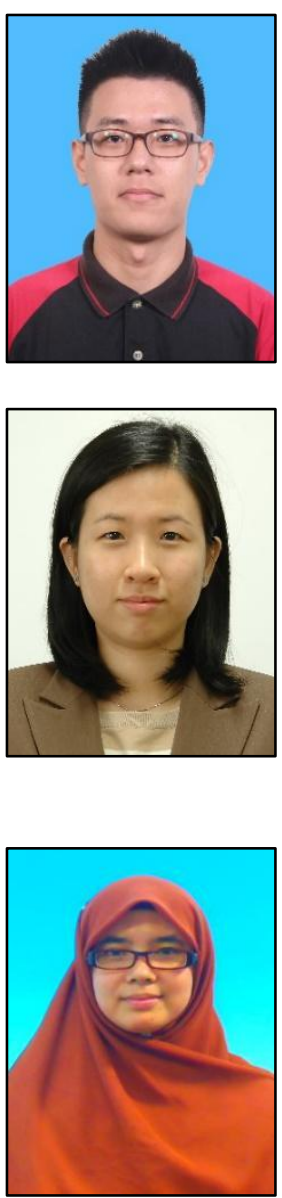

Zhong Yih Tan was born in Selangor, Malaysia. Currently, he is a final year student undertaking B. E. (Hons.) in Electrical Power Engineering at Universiti Tenaga Nasional, Malaysia. His research interests include bidirectional isolated dc-dc converters.
Nadia Tan Mei Lin received the B.Eng. (Hons.) degree from the University of Sheffield, Sheffield, U.K., in 2002, the M. Eng. degree from Universiti Tenaga Nasional, Kajang, Malaysia, in 2007, and the Ph.D. degree from Tokyo Institute of Technology, Tokyo, Japan, in 2010, all in electrical engineering. Since April 2017, she has been an Associate Professor in the Department of Electrical Power Engineering, Universiti Tenaga Nasional. Her current research interests include power conversion systems for energy storage, bidirectional isolated dc-dc converters, multilevel cascaded inverters for renewable energy applications. She is a Chartered Engineer registered with Engineering Council, United Kingdom, a Member of the Institution of Engineering and Technology (IET) and the Institute of Electrical and Electronics Engineers (IEEE), and a Graduate Member of the Institution of Engineers Malaysia (IEM).

I.S. Hussain received the B.E. (Hons.) in Electrical Engineering from the University of Southampton, U.K. and the M.E. degree from the Universiti Tenaga Nasional, Malaysia. She is currently a lecturer with Universiti Tenaga Nasional. Her interests include steady-state and dynamic analysis of ac/dc system. 